\title{
BMJ Open Evolution of target organ damage and haemodynamic parameters over 4 years in patients with increased insulin resistance: the LOD-DIABETES prospective observational study
}

\author{
Manuel Ángel Gómez-Marcos, ${ }^{1,2,3,4}$ José Ignacio Recio-Rodríguez, ${ }^{1,2,3}$ \\ María Carmen Patino-Alonso, ${ }^{1,2,5}$ Cristina Agudo-Conde, ${ }^{1,2,3}$ \\ Emiliano Rodríguez-Sanchez, ${ }^{1,2,3,4}$ Jose Angel Maderuelo-Fernandez, ${ }^{1,2,3}$ \\ Leticia Gómez-Sánchez,, ${ }^{1,2}$ Marta Gomez-Sanchez,, ${ }^{1,2}$ Luís García-Ortiz, 1,2,3,6 \\ LOD-DIABETES Group
}

To cite: Gómez-Marcos MÁ, Recio-Rodríguez JJ, Patino-Alonso MC. Evolution of target organ damage and haemodynamic parameters over 4 years in patients with increased insulin resistance: the LOD-DIABETES prospective observational study. BMJ Open 2016;6: e010400. doi:10.1136/ bmjopen-2015-010400

- Prepublication history and additional material is available. To view please visit the journal (http://dx.doi.org/ 10.1136/bmjopen-2015010400).

Received 30 October 2015 Revised 28 March 2016 Accepted 4 April 2016

\section{CrossMark}

For numbered affiliations see end of article.

Correspondence to Dr Manuel Ángel Gómez-Marcos; magomez@usal.es

\section{ABSTRACT}

Objectives: We prospectively examined the impact of type 2 diabetes compared with metabolic syndrome (MetS) on the development of vascular disease over 4 years as determined by anatomic and functional markers of vascular disease. By comparing the vascular outcomes of the 2 disorders, we seek to determine the independent effect of elevated glucose levels on vascular disease.

Setting: 2 primary care centres in Salamanca, Spain. Participants: We performed a prospective observational study involving 112 patients (68 with type 2 diabetes and 44 with MetS) who were followed for 4 years.

Primary and secondary outcome measures: Measurements included blood pressure, blood glucose, lipids, smoking, body mass index, waist circumference, Homeostasis Model Assessment Insulin Resistance (HOMA-IR), hs-c-reactive protein and fibrinogen levels. We also evaluated vascular, carotid intima media thickness (IMT), pulse wave velocity (PWV) and ankle/brachial index, heart and renal target organ damage (TOD). The haemodynamic parameters were central (CAIx) and peripheral (PAIx) augmentation indices.

Results: In year 4, participants with type 2 diabetes had increased IMT thickness. These patients had more plaques and an IMT>0.90 mm. In participants with MetS, we only found an increase in the number of plaques. We found no changes in PWV, CAlx and PAlx. The patients with diabetes had a greater frequency of vascular TOD. There were no differences neither in renal nor cardiac percentage of TOD in the patients with MetS or diabetes mellitus type 2.

Conclusions: This prospective study showed that the evolution of vascular TOD is different in participants with type 2 diabetes compared with those with MetS. While IMT and PWV increased in type 2 diabetes, these were not modified in MetS. The renal

\section{Strengths and limitations of this study}

- We analyse the evolution of target organ damage (TOD) and haemodynamic parameters over 4 years in patients with increased insulin resistance.

- The patients with diabetes had an increase in the percentage of vascular TOD as evaluated by intima media thickness and pulse wave velocity.

- The evolution of vascular TOD is different in participants with type 2 diabetes than in those with metabolic syndrome.

- The renal and cardiac TOD evolution did not change in either group.

- The number of participants per group limits the power of analysis and the two groups are not fully balanced in terms of age (4 years of difference), which may influence the course.

and cardiac TOD evolution, as well as the PAlx and CAlx, did not change in either group.

Trial registration number: NCT01065155; Results.

\section{INTRODUCTION}

Cardiovascular disease morbidity-mortality is greater in people with type 2 diabetes or metabolic syndrome (MetS). ${ }^{12}$ MetS and type 2 diabetes are conditions characterised by insulin resistance; type 2 diabetes is further characterised by increased glucose levels. Both conditions are strongly associated with vascular disease through risk factors that associate with insulin resistance such as hypertension, increased lipid levels and increased inflammation levels. ${ }^{3-7}$ The presence of 
target organ damage (TOD) vascular, ${ }^{8-11}$ cardiac $^{12}$ and renal $^{13}{ }^{14}$ increases the risk of cardiovascular complications independently of the existing estimated risk.

The individual role of elevated glucose levels in the development of vascular disease-independent of the other vascular risk factors-is uncertain. Here, we examined a cohort with insulin resistance: one with MetS only and the other with type 2 diabetes.

We prospectively examined the impact of type 2 diabetes versus MetS on the development of vascular disease over 4 years as determined by anatomic and functional markers of vascular disease. By comparing the vascular outcomes of the two disorders, we sought to determine the independent effect of elevated glucose levels on vascular disease.

\section{METHODS}

\section{Study design}

A prospective observational study was carried out in the primary care setting with a follow-up of 4 years. This study analysed 112 participants who were included in the LOD-DIABETES study (NCT01065155). ${ }^{15}$

\section{Study population}

Using consecutive sampling, we enrolled 112 patients who visited their family physician between January 2009 and January 2010 with type 2 diabetes $(n=68)$, as defined by the American Diabetes Association criteria, ${ }^{16}$ or MetS $(\mathrm{n}=44)$, as defined according to the National Cholesterol Education Program, ATP III. ${ }^{17}$ The exclusion criteria included patients unable to comply with the protocol requirements such as psychological and/or cognitive disorders, failure to cooperate, educational limitations, problems in understanding the written language and failure to sign the informed consent document. Patients participating or programmed to participate in a clinical trial during the study were also excluded, as were patients with serious comorbidities representing a threat to life over the subsequent 12 months.

The sample size was estimated to detect statistically significant differences in carotid intima media thickness (IMT) $\geq 0.03 \mathrm{~mm}$ between baseline and 4 years. We used an $\alpha$ risk of 0.05 and a $\beta$ risk of 0.2 in a two-sided test. We further assumed an SD of $0.11 \mathrm{~mm}$ based on previous studies showing that 112 participants are necessary. ${ }^{18}$ We anticipated a dropout rate of $5 \%$. An independent ethics committee of health area of Salamanca (Spain) approved the study. All participants gave informed written consent according to the general recommendations of the Declaration of Helsinki. ${ }^{19}$

\section{Measurement}

A detailed description has been published elsewhere on how the clinical data were collected including anthropometric measurements, blood pressure and TOD assessment. $^{15}$

\section{Blood pressure}

Three measurements of systolic (SBP) and diastolic blood pressure (DBP) were collected with a validated OMRON model M7 sphygmomanometer (Omron Health Care, Kyoto, Japan). We used the average of the last two according to the recommendations of the European Society of Hypertension. ${ }^{20}$

\section{Vascular assessment}

Carotid femoral pulse wave velocity and peripheral and central augmentation index

These parameters were estimated using the SphygmoCor System (AtCor Medical Pty Ltd, Head Office, West Ryde, Australia). The pulse wave velocity (PWV) was estimated with patients in the supine position. The pulse wave of the carotid and femoral arteries was analysed to estimate the delay with respect to the ECG wave and to calculate PWV. Distance measurements were collected with a measuring tape from the sternal notch to the carotid and femoral arteries at the sensor location. We considered TOD if PWV was higher than $12 \mathrm{~m} / \mathrm{s}^{21}$

The central augmentation index (CAIx) is a composite index that integrates the amount of the wave that is reflected back to the aorta depending on the tone of the resistance arteries-these are the main peripheral reflecting sites. We used Px Pulse Wave Analysis with the patient in the sitting position and the arm resting on a rigid surface. The site of study was the radial artery. A mathematical transformation estimated the aortic pulse wave. The reliability of these measurements was evaluated before the study using the CAIx intraclass correlation coefficient, which showed values of 0.97 (95\% CI 0.94 to 0.99 ) for intraobserver agreement on 22 repeat measurements.

According to the Bland-Altman analysis, the mean difference for intraobserver agreement $(95 \%$ limits of agreement) was 0.45 ( -9.88 to 10.79 ). From the morphology of the aortic wave, the CAIx was estimated using the following formula: increase in central pressure $\times 100$ / pulse pressure. The value was adjusted to a heart rate of 75 by the SphygmoCor System device.

The peripheral augmentation index (PAIx) is a measurement taken directly from the late systolic shoulder of the peripheral arterial waveform. It is the ratio of the difference in amplitude between the second peak and the diastolic pressure over the difference between the first peak and the diastolic pressure. ${ }^{22}$ The PAIx was calculated as: (second peak SBP (SBP2)-DBP)/(first peak $\mathrm{SBP}-\mathrm{DBP}) \times 100$. This gave a per cent $(\%)$ value. ${ }^{22}$

\section{Assessment of vascular structure by carotid IMT}

Carotid ultrasound was used to assess carotid IMT by two investigators trained in this protocol prior to starting the study. The reliability of such recordings was evaluated before the study using the intraclass correlation coefficient, which showed values of 0.97 (95\% CI 0.94 to 0.99 ) for intraobserver agreement on repeated measurements in 20 participants and 0.90 (95\% CI 0.74 to 0.96) for interobserver agreement. According to the Bland-Altman 
analysis, the mean difference for interobserver agreement $(95 \%$ limits of agreement) was 0.01 ( -0.03 to 0.06$)$. A Sonosite Micromax ultrasound (Sonosite Inc, Bothell, Washington, USA) device paired with a $5-10 \mathrm{MHz}$ multifrequency high-resolution linear transducer with Sonocal software was used for automatic measurements of IMT to optimise reproducibility. Measurements were made on the common carotid after examining a $10 \mathrm{~mm}$ longitudinal section $1 \mathrm{~cm}$ from the bifurcation. Measurements were also performed at the proximal and distal walls in the lateral, anterior and posterior projections. They followed an axis perpendicular to the artery to discriminate two lines-one for the intima-blood interface and the other for the media-adventitious interface. Six measurements were obtained for the right carotid and six measurements for the left carotid. We used the average values (average IMT) as automatically calculated by the software. ${ }^{23}$ The measurements were obtained with the participant lying down with the head extended and slightly turned opposite to the carotid artery under study. We considered the average TOD if the IMT mean was $>0.90 \mathrm{~mm}$ or if there were atherosclerotic plaques with a diameter of $1.5 \mathrm{~mm}$ or a focal increase in $0.5 \mathrm{~mm}$ or $50 \%$ of the adjacent IMT. ${ }^{21}$

\section{Evaluation of peripheral artery involvement}

This was assessed using the ankle-brachial index (ABI) and was calculated in the morning for patients who had not drunk coffee or smoked tobacco for at least 8 hours prior to the measurement. The room temperature was $22-24^{\circ} \mathrm{C}$. Patients were supine with the feet uncovered. The pressure in the lower limbs was measured after resting for 20 min using a portable Watch BP Office for assessing the ABI (Microlife AG Swiss Corporation Espenstrasse 139; CH-9443 Widnau/Switzerland). The ABI was calculated automatically for each foot by dividing the higher of the two systolic pressures in the ankle by the higher of the two systolic pressures in the arm. An ABI $<0.9$ was considered peripheral artery TOD. ${ }^{20}$

\section{Renal assessment}

Kidney damage was assessed by measuring the creatinine plasma concentration and glomerular filtration rate (eGFR) as estimated according to the Modification of Diet
Figure 1 Study flow chart. The participants were analysed each year for cardiovascular events in each group. We include the evolution of patients with MetS to type 2 diabetes. CV, cerebrovascular; MetS, metabolic syndrome; DM, type 2 diabetes.

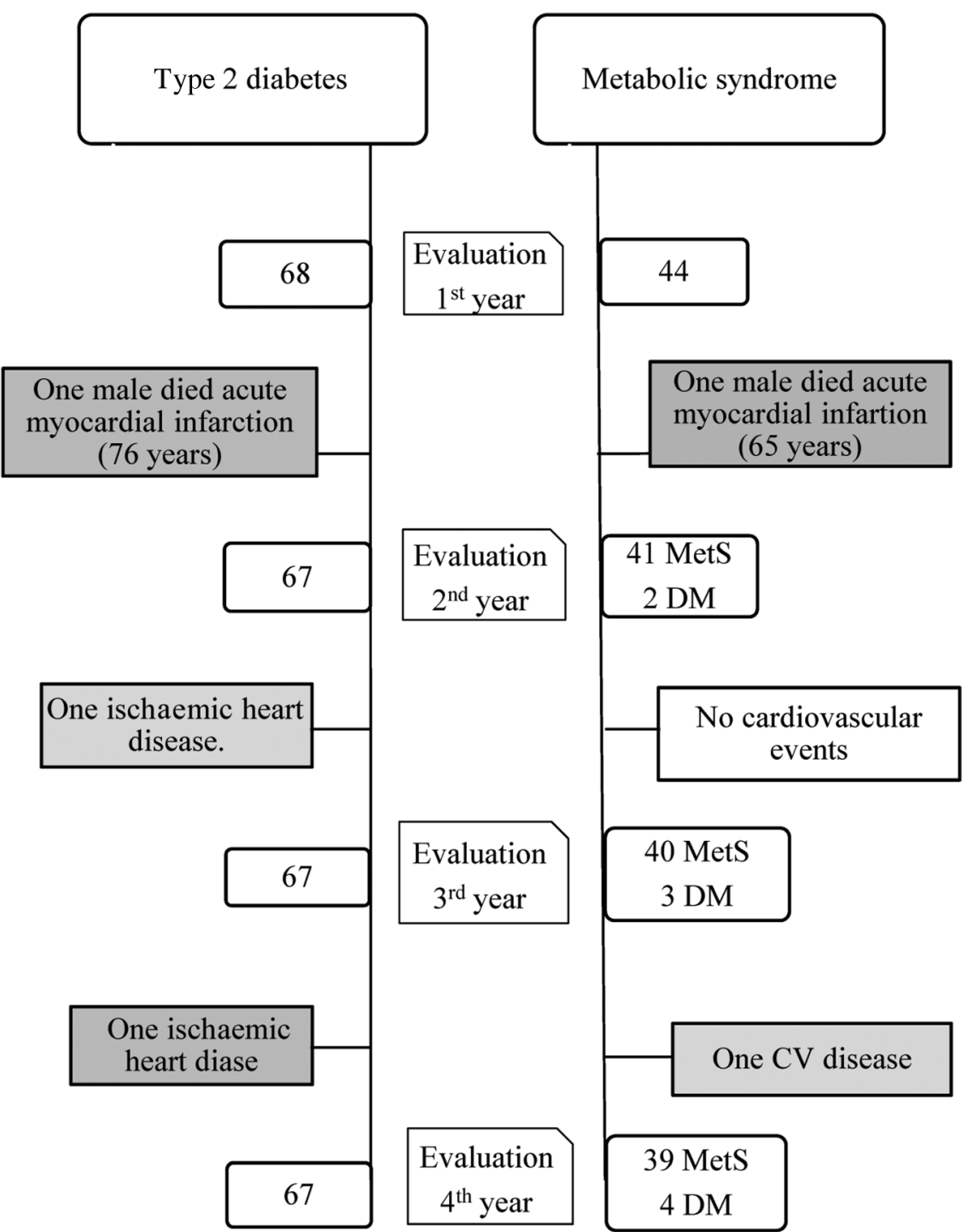


Table 1 Changes in cardiovascular risk factors and medications used in patients with diabetes mellitus and metabolic syndrome

\begin{tabular}{|c|c|c|c|c|c|}
\hline Patients with type 2 diabetes mellitus & 1st year $(n=68)$ & 2nd year $(n=67)$ & 3rd year $(n=67)$ & 4th year $(n=67)$ & p Value \\
\hline Smokers, n (\%) & $16(23.5)$ & $16(25.0)$ & $15(22.4)$ & 15(22.4) & 0.733 \\
\hline Ischaemic heart disease, $\mathrm{n}(\%)$ & $8(11.8)$ & $8(12.5)$ & $9(13.4)$ & $9(13.4)$ & 0.392 \\
\hline Cerebrovascular disease, $\mathrm{n}(\%)$ & $2(2.9)$ & $2(2.5)$ & $2(3.0)$ & $2(3.0)$ & 1.000 \\
\hline $\mathrm{BMI}\left(\mathrm{kg} / \mathrm{m}^{2}\right)$ & $30.1 \pm 5.0$ & $29.7 \pm 5.3$ & $29.8 \pm 5.4$ & $29.8 \pm 5.4$ & 0.243 \\
\hline Waist circumference (cm) & $102.9 \pm 12.7$ & $101.6 \pm 13.7$ & $102.1 \pm 13.6$ & $102.5 \pm 13.1$ & 0.453 \\
\hline Total cholesterol (mg/dL) & $187.5 \pm 34.0$ & $185.8 \pm 37.1$ & $182.4 \pm 26.5$ & $176.94 \pm 31.1$ & 0.065 \\
\hline Triglycerides (mg/dL) & $143.9 \pm 68.3$ & $141.6 \pm 76.0$ & $142.9 \pm 75.4$ & $139.1 \pm 70.8$ & 0.913 \\
\hline LDL cholesterol (mg/dL) & $108.6 \pm 28.5$ & $108.0 \pm 28.9$ & $102.3 \pm 25.6$ & $100.7 \pm 28.0$ & 0.089 \\
\hline HDL cholesterol $(\mathrm{mg} / \mathrm{dL}) \S$ & $48.6 \pm 11.7$ & $48.5 \pm 12.1$ & $51.6 \pm 13.8$ & $50.5 \pm 12.4$ & 0.035 \\
\hline Serum glucose (mg/dL) & $126.7 \pm 35.3$ & $132.5 \pm 45.8$ & $129.1 \pm 44.6$ & $127.4 \pm 35.7$ & 0.538 \\
\hline $\mathrm{HbA1c}(\%)$ & $6.96 \pm 1.17$ & $7.0 \pm 1.32$ & $7.0 \pm 1.06$ & $6.9 \pm 1.08$ & 0.433 \\
\hline $\mathrm{HbA} 1 \mathrm{c}(\mathrm{mmol} / \mathrm{mol})$ & $51 \pm 12.78$ & $53 \pm 14.52$ & $53 \pm 11.56$ & $52 \pm 11.83$ & 0.448 \\
\hline HOMA-IR & $3.29 \pm 2.73$ & $3.30 \pm 3.80$ & $2.61 \pm 4.42$ & $3.12 \pm 2.51$ & 0.062 \\
\hline hs-c-reactive protein (mg/dL) & $0.34 \pm 0.51$ & $0.31 \pm 0.42$ & $0.31 \pm 0.52$ & $0.33 \pm 0.69$ & 0.465 \\
\hline Fibrinogen (mg/dL) & $337.2 \pm 61.2$ & $365.8 \pm 93.2$ & $350.9 \pm 73.5$ & $339.9 \pm 74.7$ & 0.064 \\
\hline Office SBP (mm Hg) & $136.1 \pm 19.1$ & $132.49 \pm 18.8$ & $134.8 \pm 18.1$ & $133.4 \pm 18.2$ & 0.536 \\
\hline Office DBP $(\mathrm{mm} \mathrm{Hg})^{*}, \ddagger, \| I, \S$ & $82.6 \pm 11.6$ & $78.9 \pm 9.8$ & $79.2 \pm 9.1$ & $75.3 \pm 10.3$ & $<0.01$ \\
\hline Mean antihypertensive drugs $\dagger$ & $1.51 \pm 1.16$ & $1.60 \pm 1.21$ & $1.84 \pm 1.27$ & $1.75 \pm 1.31$ & 0.012 \\
\hline Antihypertensive drugs, n (\%) & $51(76.1)$ & $51(76.1)$ & $55(82.1)$ & $52(77.6)$ & 0.187 \\
\hline Mean lipid-lowering drugs & $0.70 \pm 0.55$ & $0.70 \pm 0.55$ & $0.79 \pm 0.57$ & $0.81 \pm 0.56$ & 0.037 \\
\hline Lipid-lowering drugs, n (\%) & $44(65.7)$ & $44(65.7)$ & $48(71.6)$ & $49(73.1)$ & 0.274 \\
\hline Mean antidiabetic drugst,§ & $1.36 \pm 0.73$ & $1.34 \pm 0.75$ & $1.55 \pm 0.8$ & $1.42 \pm 0.76$ & 0.018 \\
\hline Antidiabetic drugs, $\mathrm{n}(\%)$ & $62(92.5)$ & $61(91.0)$ & $64(95.5)$ & $63(94.0)$ & 0.463 \\
\hline Patients with metabolic syndrome & 1st year $(n=44)$ & 2 nd year $(n=43)$ & 3rd year $(n=43)$ & 4 th year $(n=43)$ & $p$ Value \\
\hline Smokers, n (\%) & $9(20.5)$ & $9(20.9)$ & $4(9.3)$ & $4(9.3)$ & 0.007 \\
\hline Ischaemic heart disease, $n(\%)$ & $2(4.5)$ & $2(4.7)$ & $2(4.7)$ & $2(4.7)$ & 1.000 \\
\hline Cerebrovascular disease, $\mathrm{n}(\%)$ & $0(0.0)$ & $0(0.0)$ & $0(0.0)$ & $1(2.3)$ & 0.392 \\
\hline BMI $(\mathrm{kg} / \mathrm{m} 2)$ & $31.1 \pm 3.5$ & $30.8 \pm 4.1$ & $31.1 \pm 4.1$ & $30.6 \pm 3.6$ & 0.183 \\
\hline Waist circumference (cm) & $104.8 \pm 9.8$ & $104.8 \pm 9.0$ & $105.7 \pm 9.6$ & $103.6 \pm 9.7$ & 0.059 \\
\hline Total cholesterol (mg/dL)‡ & $219.0 \pm 44.2$ & $208.5 \pm 41.3$ & $206.0 \pm 38.0$ & $198.4 \pm 28.8$ & 0.012 \\
\hline Triglycerides(mg/dL) & $167.7 \pm 53.1$ & $151.0 \pm 83.7$ & $155.5 \pm 106.1$ & $149.9 \pm 147.8$ & 0.761 \\
\hline LDL cholesterol (mg/dL)‡ & $140.3 \pm 39.7$ & $130.6 \pm 35.9$ & $126.0 \pm 34.8$ & $123.1 \pm 27.3$ & 0.017 \\
\hline HDL cholesterol $(\mathrm{mg} / \mathrm{dL}) \dagger, \ddagger, \S$ & $45.2 \pm 11.0$ & $47.4 \pm 11.4$ & $50.1 \pm 11.7$ & $49.7 \pm 10.8$ & $<0.01$ \\
\hline Serum glucose $(\mathrm{mg} / \mathrm{dL})$ & $92.67 \pm 11.8$ & $88.9 \pm 12.5$ & $90.7 \pm 14.3$ & $89.6 \pm 12.9$ & 0.190 \\
\hline HbA1c (\%) & $5.6 \pm 0.67$ & $5.8 \pm 0.32$ & $5.8 \pm 0.32$ & $5.7 \pm 0.42$ & 0.169 \\
\hline $\mathrm{HbA} 1 \mathrm{c}(\mathrm{mmol} / \mathrm{mol})$ & $37 \pm 7.30$ & $38 \pm 3.46$ & $39 \pm 3.52$ & $39 \pm 4.63$ & 0.130 \\
\hline HOMA-IR* & $2.98 \pm 1.82$ & $2.22 \pm 1.30$ & $2.21 \pm 1.37$ & $2.51 \pm 1.64$ & 0.007 \\
\hline hs-c-reactive protein (mg/dL) & $0.26 \pm 0.21$ & $0.27 \pm 0.25$ & $0.39 \pm 0.42$ & $0.22 \pm 0.19$ & 0.107 \\
\hline Fibrinogen $(\mathrm{mg} / \mathrm{dL}) \dagger$ & $327.1 \pm 59.1$ & $345.2 \pm 66.6$ & $368.1 \pm 74.4$ & $347.7 \pm 51.9$ & 0.001 \\
\hline Office SBP $(\mathrm{mm} \mathrm{Hg})^{\star}, \ddagger, \emptyset$ & $142.4 \pm 12.5$ & $135.0 \pm 15.5$ & $136.5 \pm 13.2$ & $129.6 \pm 12.3$ & $<0.01$ \\
\hline Office DBP (mm Hg)‡,II,ף & $88.6 \pm 9.6$ & $84.9 \pm 10.3$ & $84.9 \pm 10.9$ & $79.2 \pm 8.2$ & $<0.01$ \\
\hline Mean antihypertensive drugs ${ }^{\star}, \dagger, \ddagger$ & $0.77 \pm 0.10$ & $1.37 \pm 1.20$ & $1.42 \pm 1.22$ & $1.49 \pm 0.94$ & $<0.01$ \\
\hline Antihypertensive drugs, $n(\%)^{*}, \dagger, \ddagger$ & $20(46.5)$ & $31(72.1)$ & $30(69.8)$ & $36(83.7)$ & $<0.01$ \\
\hline Mean lipid-lowering drugs†,‡ & $0.30 \pm 0.46$ & $0.44 \pm 0.55$ & $0.51 \pm 0.59$ & $0.51 \pm 0.55$ & 0.001 \\
\hline Lipid-lowering drugs, n (\%)‡ & $13(30.2)$ & $19(44.2)$ & $20(46.5)$ & $21(48.8)$ & 0.003 \\
\hline
\end{tabular}

Data for qualitative variables are expressed as $\mathrm{n}$ : number $(\%)$ and for quantitative variables as mean \pm SD.

${ }^{*} \mathrm{p}<0.05$ between first and second year.

$t p<: 0.05$ between first and third year.

$\neq \mathrm{p}<0.05$ between first and fourth year.

$\S p<0.05$ between second and third year.

$\| \mathrm{p}<0.05$ between second and fourth year.

Ip $<0.05$ between third and fourth year.

BMI, body mass index; DBP, diastolic blood pressure; HbA1c, glycosylated haemoglobin; HDL, high-density lipoprotein; HOMA-IR,

Homeostasis Model Assessment Insulin Resistance; LDL, low-density lipoprotein; SBP, systolic blood pressure.

in Renal Disease-Isotopic Dilution Mass Spectrometry (MDRD-IDMS).${ }^{24}$ Proteinuria was assessed by the albumin/ creatinine ratio following the 2013 European Society of Hypertension/European Society of Cardiology Guidelines criteria. The TOD renal was defined as $1.3 \mathrm{mg}$ plasma creatinine per $100 \mathrm{~mL}$ or higher in men and $1.2 \mathrm{mg}$ per $100 \mathrm{~mL}$ or higher in women, as well as an eGFR below $60 \mathrm{~mL} / \mathrm{min}$ or albumin/creatinine ratio $\geq 30 \mathrm{mg} / \mathrm{g} .{ }^{20}$ 
Table 2 Changes in target organ damage and arterial stiffness in patients with type 2 diabetes mellitus and metabolic syndrome

1st year $(n=68) \quad$ 2nd year $(n=67) \quad 3$ rd year $(n=67) \quad 4$ th year $(n=67) \quad p$ Value

\begin{tabular}{|c|c|c|c|c|c|}
\hline \multicolumn{6}{|l|}{ Patients with type 2 diabetes mellitus } \\
\hline \multicolumn{6}{|l|}{ Vascular } \\
\hline Carotid IMT average $(\mathrm{mm}) \ddagger, \|, \emptyset$ & $0.76 \pm 0.12$ & $0.76 \pm 0.10$ & $0.76 \pm 0.13$ & $0.80 \pm 0.12$ & $<0.01$ \\
\hline Carotid IMT average $>0.90 \mathrm{~mm}, \mathrm{n}(\%)$ & $5(7.6)$ & $4(6.0)$ & $6(9.0)$ & $10(14.9)$ & 0.021 \\
\hline $\begin{array}{l}\text { Carotid IMT maxima average } \\
(\mathrm{mm}) \ddagger, \|, \emptyset\end{array}$ & $0.94 \pm 0.14$ & $0.94 \pm 0.13$ & $0.92 \pm 0.15$ & $0.99 \pm 0.15$ & $<0.01$ \\
\hline \multicolumn{6}{|l|}{$\begin{array}{l}>0.90 \mathrm{~mm} \\
\mathrm{n}(\%)\end{array}$} \\
\hline Plaques carotid, n (\%) & $16(23.9)$ & $15(22.4)$ & $20(29.9)$ & $24(35.8)$ & 0.016 \\
\hline$A B I^{*}, \dagger, \|$ & $1.11 \pm 0.13$ & $1.20 \pm 0.12$ & $1.18 \pm 0.13$ & $1.15 \pm 0.12$ & $<0.01$ \\
\hline $\mathrm{PWV}(\mathrm{m} / \mathrm{s})$ & $9.59 \pm 2.32$ & $9.78 \pm 2.50$ & $9.84 \pm 2.47$ & $10.22 \pm 2.81$ & 0.219 \\
\hline CAIx & $30.44 \pm 9.33$ & $28.24 \pm 11.56$ & $2416 \pm 13.74$ & $27.27 \pm 12.38$ & 0.151 \\
\hline PAlx & $96.05 \pm 21.00$ & $82.59 \pm 19.44$ & $94.94 \pm 23.94$ & $93.58 \pm 28.98$ & 0.744 \\
\hline \multicolumn{6}{|l|}{ Renal } \\
\hline Serum creatinine $(\mathrm{mg} / \mathrm{dL})$ & $0.86 \pm 0.17$ & $0.86 \pm 0.21$ & $0.83 \pm 0.20$ & $0.87 \pm 0.23$ & 0.092 \\
\hline eGFR $\left(\mathrm{mL} / \mathrm{min} / 1.73 \mathrm{~m}^{2}\right)$ & $90.50 \pm 18.15$ & $92.01 \pm 20.70$ & $94.69 \pm 20.48$ & $89.64 \pm 21.20$ & 0.081 \\
\hline Albumin/creatinine ratio $(\mathrm{mg} / \mathrm{g})$ & $35.26 \pm 83.19$ & $33.51 \pm 74.36$ & $37.62 \pm 115.57$ & $50.95 \pm 159.81$ & 0.246 \\
\hline \multicolumn{6}{|l|}{ Heart } \\
\hline Cornell VDP (mm/ms) & $1648.15 \pm 659.62$ & $1584.79 \pm 522.69$ & $1658.15 \pm 665.41$ & $1657.46 \pm 722.40$ & 0.822 \\
\hline Sokolow $(\mathrm{mm} / \mathrm{ms}) \S$ & $19.28 \pm 6.08$ & $18.56 \pm 6.09$ & $20.39 \pm 6.24$ & $19.150 \pm 6.39$ & 0.008 \\
\hline \multicolumn{6}{|l|}{ Patients with metabolic syndrome } \\
\hline \multicolumn{6}{|l|}{ Vascular } \\
\hline Carotid IMT average (mm) & $0.75 \pm 0.12$ & $0.76 \pm 0.12$ & $0.73 \pm 0.10$ & $0.74 \pm 0.11$ & 0.177 \\
\hline $\begin{array}{l}\text { Carotid IMT average }>0.90 \mathrm{~mm} \text {, } \\
\mathrm{n}(\%) \dagger, \S\end{array}$ & $4(9.5)$ & $4(9.3)$ & $2(4.7)$ & $3(7.0)$ & 0.300 \\
\hline Carotid IMT maxima average $(\mathrm{mm})$ & $0.93 \pm 0.15$ & $0.93 \pm 0.15$ & $0.89 \pm 0.12$ & $0.92 \pm 0.15$ & 0.109 \\
\hline Carotid IMT maxima average & $23(53.5)$ & $23(53.5)$ & $15(34.9)$ & $19(44.2)$ & 0.019 \\
\hline \multicolumn{6}{|l|}{$\begin{array}{l}>0.90 \mathrm{~mm} \\
\mathrm{n}(\%)\end{array}$} \\
\hline Plaques carotid, n (\%) & $3(7.0)$ & $3(7.0)$ & $5(11.6)$ & $8(18.6)$ & 0.014 \\
\hline $\mathrm{ABI} \dagger$ & $1.12 \pm 0.12$ & $1.17 \pm 0.09$ & $1.20 \pm 0.11$ & $1.17 \pm 0.08$ & 0.006 \\
\hline $\mathrm{PWV}(\mathrm{m} / \mathrm{s})$ & $9.29 \pm 2.70$ & $8.57 \pm 2.22$ & $8.90 \pm 2.08$ & $8.61 \pm 2.02$ & 0.068 \\
\hline CAlx & $28.65 \pm 11.00$ & $25.98 \pm 10.54$ & $26.12 \pm 11.36$ & $26.81 \pm 14.51$ & 0.290 \\
\hline PAlx & $94.55 \pm 29.51$ & $90.56 \pm 20.60$ & $91.08 \pm 25.95$ & $89.90 \pm 22.51$ & 0.453 \\
\hline \multicolumn{6}{|l|}{ Renal } \\
\hline Serum creatinine $(\mathrm{mg} / \mathrm{dL})$ & $0.89 \pm 0.16$ & $0.90 \pm 0.19$ & $0.87 \pm 0.18$ & $0.87 \pm 0.16$ & 0.164 \\
\hline eGFR $\left(\mathrm{mL} / \mathrm{min} / 1.73 \mathrm{~m}^{2}\right) \S, \|$ & $87.64 \pm 14.05$ & $87.33 \pm 18.75$ & $91.24 \pm 18.17$ & $90.29 \pm 17.75$ & 0.252 \\
\hline Albumin/creatinine ratio $(\mathrm{mg} / \mathrm{g})$ & $15.81 \pm 38.23$ & $28.33 \pm 133.22$ & $4.68 \pm 10.15$ & $4.08 \pm 7.23$ & 0.297 \\
\hline \multicolumn{6}{|l|}{ Heart } \\
\hline Cornell VDP $(\mathrm{mm} / \mathrm{ms})^{\star}$ & $1477.67 \pm 459.16$ & $1661.89 \pm 536.98$ & $1616.19 \pm 539.66$ & $1521.41 \pm 500.32$ & 0.004 \\
\hline Sokolow $(\mathrm{mm} / \mathrm{ms}) \S, \|$ & $20.82 \pm 5.83$ & $19.54 \pm 5.54$ & $21.94 \pm 6.19$ & $21.37 \pm 6.13$ & $<0.01$ \\
\hline
\end{tabular}

Data for qualitative variables are expressed as $\mathrm{n}$ : number and (\%) and quantitative variables as mean $\pm \mathrm{SD}$.

${ }^{*} \mathrm{p}<0.05$ between first and second year.

$\mathrm{tp}<0.05$ between first and third year.

$\neq \mathrm{p}<0.05$ between first and fourth year.

$\S p<0.05$ between second and third year.

$\| p<0.05$ between second and fourth year.

Ip $<0.05$ between third and fourth year.

$\mathrm{ABI}$, ankle brachial index; CAIx, central augmentation index; Cornell VDP, Cornell voltage duration product; eGFR, estimated glomerular filtration rate; IMT, intima media thickness carotid; PAIx, peripheral augmentation index; PWV, pulse wave velocity.

\section{Cardiac assessment}

The ECG examination was performed using a General Electric MAC V.3.500 ECG System (General Electric, Niskayuna, New York, USA) that automatically measures the voltage and duration of waves and estimates the criteria of the Cornell voltage-duration product (Cornell
VDP) and the Sokolow Lyon product. ${ }^{25}$ The TOD heart was defined according to the 2013 European Society of Hypertension/European Society of Cardiology Guidelines criteria (Sokolow-Lyon index $(\mathrm{SV} 1+\mathrm{RV} 5>3.5 \mathrm{mV})$, the modified Sokolow-Lyon index (largest S-wave+largest R-wave $>3.5 \mathrm{mV}$ ) or the Cornell 
voltage QRS duration product $(>2440 \mathrm{mV} \mathrm{ms}){ }^{21}$ The individuals performing the different tests were blinded to the clinical data. All assessments were made within 10 days.

\section{Statistics}

Continuous variables were expressed as a mean $\pm \mathrm{SD}$ and qualitative variables used a frequency distribution. We analysed changes in quantitative variables at follow-up with repeated analysis with the General Lineal Model (GLM) procedure corrected by the Bonferroni method. We considered the presence or absence of sphericity and performed the Greenhouse and Geisser correction. The IMT and PWV were analysed with repeated measurements unadjusted and adjusted for age, gender, office mean blood pressure and atherogenic index. We used the Cochran tests to contrast the hypothesis of two or more related proportions. The data were analysed using the SPSS V.20.0
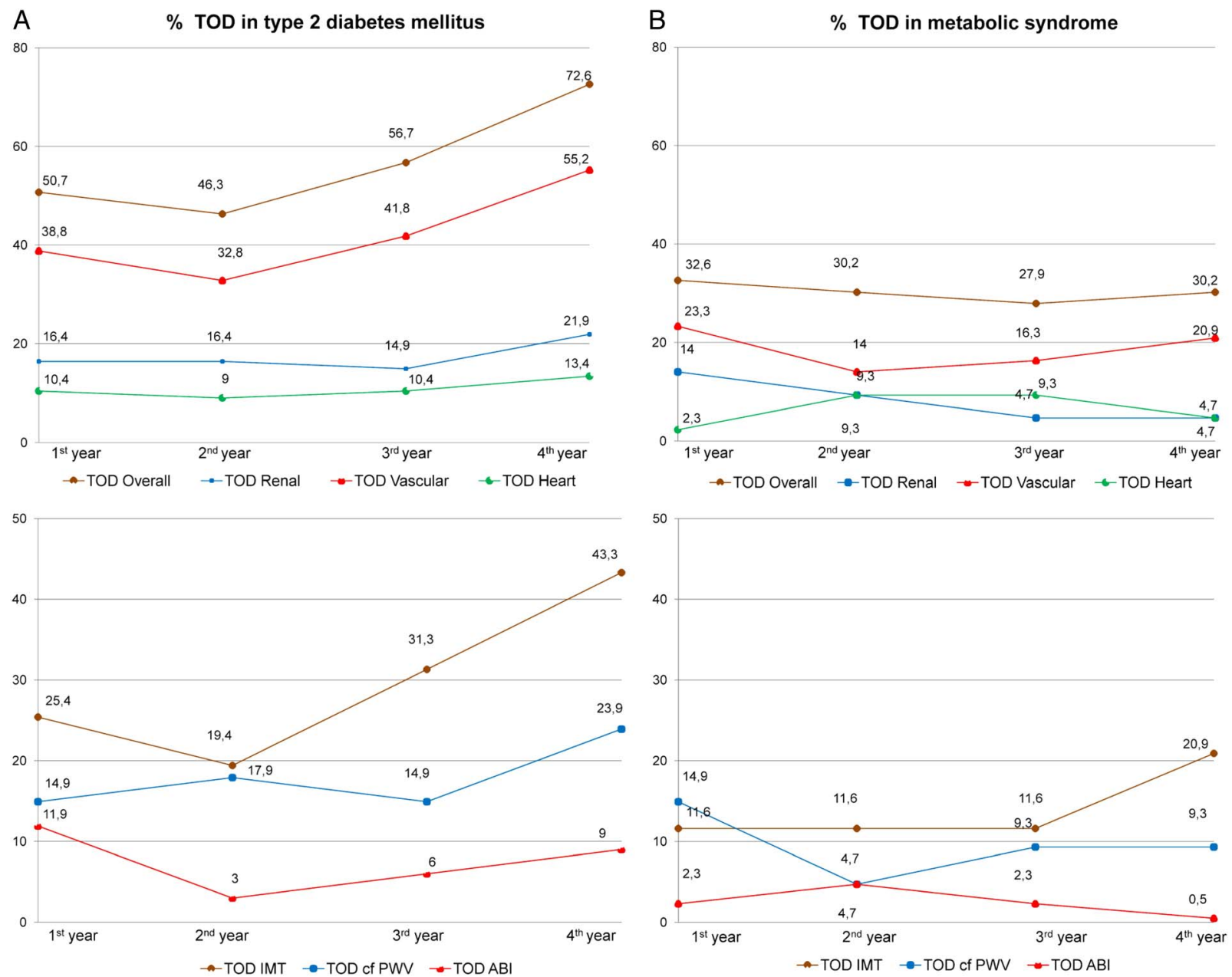

Figure 2 Changes between the 4 years of follow-up in TOD. (A) TOD in type 2 diabetes. (B) TOD in metabolic syndrome. In type 2 diabetes: $p<0.01$ in TOD overall, TOD vascular, carotid and cf-PWV. IMT, intima media thickness; cf-PWV, carotid femoral pulse wave velocity; $\mathrm{ABI}$, ankle brachial index; GFR, glomerular filtration rate; $\mathrm{ACR}$, albumin creatinine ratio; TOD, target organ damage.

statistical package (SPSS Inc, Chicago, Illinois, USA). A value of $\mathrm{p}<0.05$ was considered statistically significant.

\section{RESULTS}

Throughout the first year of follow-up, two males died as a result of acute myocardial infarction-one with type 2 diabetes and the other with MetS (aged 76 and 65 years, respectively). Subsequently, two non-fatal cardiovascular events occurred in the type 2 diabetes group. In the MetS group, there was a cerebrovascular event, and four participants developed type 2 diabetes. The flow chart is shown in figure 1.

The mean age was $57 \pm 12$ years $(60 \pm 12$ years in diabetic people and $55 \pm 12$ years in MetS). The frequency of males was $63.4 \%$ (63.2\% in people with diabetes, $63.6 \%$ in those with MetS).

Table 1 shows the cardiovascular risk factors, biochemical data and drugs analysed in each of the four evaluations in participants with type 2 diabetes and MetS. The evolution time of diabetes type 2 from the moment of

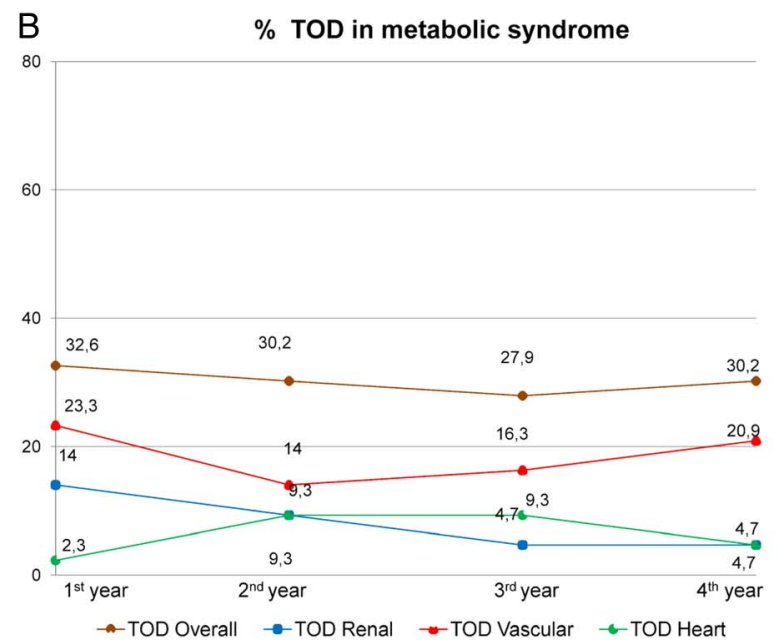


the diagnosis was over two years. Table 2 shows the annual assessments of vascular, renal and cardiac TOD in patients with type 2 diabetes and MetS.

Type 2 diabetes had increased IMT, with more participants presenting with plaques, and a higher percentage of participants with IMT $>0.9 \mathrm{~mm}$ in the follow-up. There were also changes in the ABI $(\mathrm{p}<0.01)$ and the Sokolow criteria.

Likewise, in participants with MetS, there were changes in the number of participants with a mean maximum IMT $>0.9 \mathrm{~mm}$ and the percentage of participants with plaques $(\mathrm{p}=0.014)$. There were also changes in the ABI $(p=0.006)$ in the Sokolow and Cornell PDV criteria.

The average IMT mean increased by $0.010 \mathrm{~mm}$ in patients with diabetes and by $0.001 \mathrm{~mm}$ in participants with MetS per year $(p=0.011)$. PWV increased by $0.162 \mathrm{~m} / \mathrm{s}$ in patients with diabetes and decreased by $0.182 \mathrm{~m} / \mathrm{s}$ in participants with MetS per year $(\mathrm{p}=0.002)$. Figure 2A, B shows the trend and the percentage of patients with type 2 diabetes or MetS with vascular, renal

and cardiac TOD in each of the four measurements. The most prevalent TOD in both groups is carotid artery injury (43\% in type 2 diabetes and $21 \%$ in MetS) in the last assessment.

In participants with type 2 diabetes, the percentage of patients with overall and vascular TOD increased $(p<0.01)$. We found no changes in TOD in patients with MetS.

In the unadjusted repeated measurement analyses, we found differences in IMT $(p=0.002)$, but not in PWV ( $p=0.709$; figure 3A-D). After adjusting for age, gender, mean blood pressure and atherogenic index, the differences in the 4 years of follow-up of IMT disappeared ( $p=0.909)$, but did not modify PWV ( $p=0.223)$. Adjusted for age, this is only seen in online supplementary figures S1A and S1B. An interaction effect is observed between the IMT $\times$ group $(p=0.004)$ and the $P W V \times$ group ( $p=0.033$ ). Thus, from the third year, both IMT and PWV are higher in participants with type 2 diabetes than in those with MetS (figure 3). However, in the post hoc
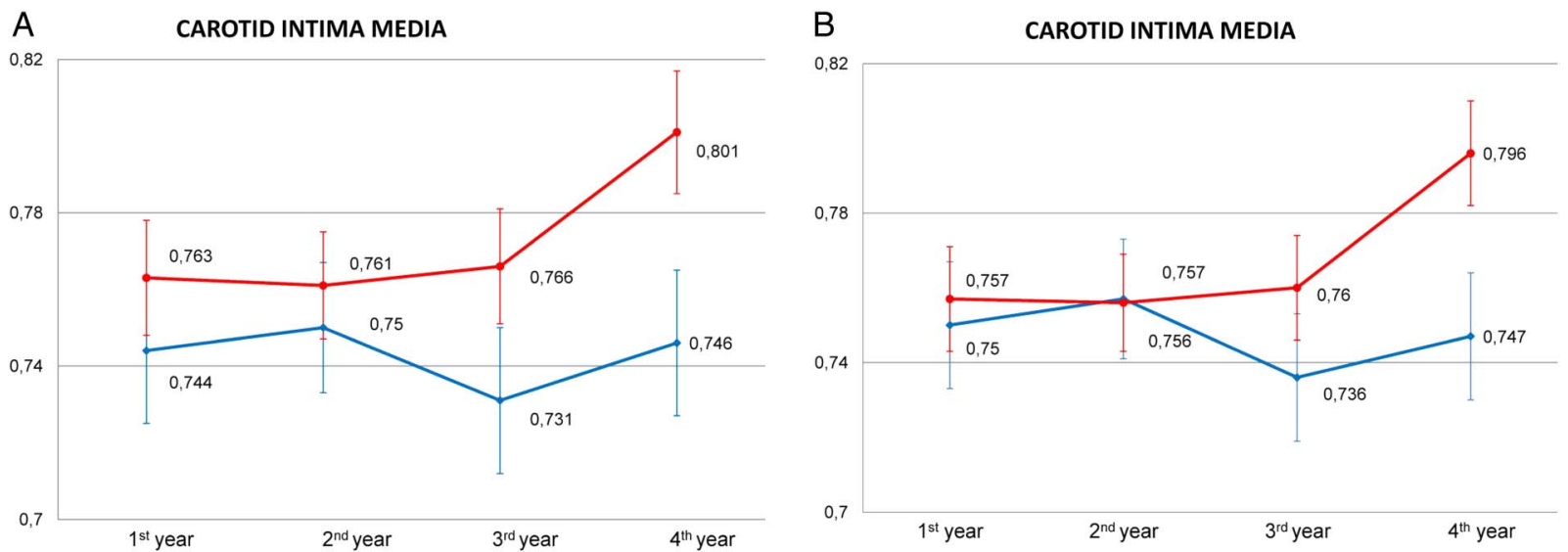

- Metabolic syndrome $\rightarrow$ Diabetes mellitus
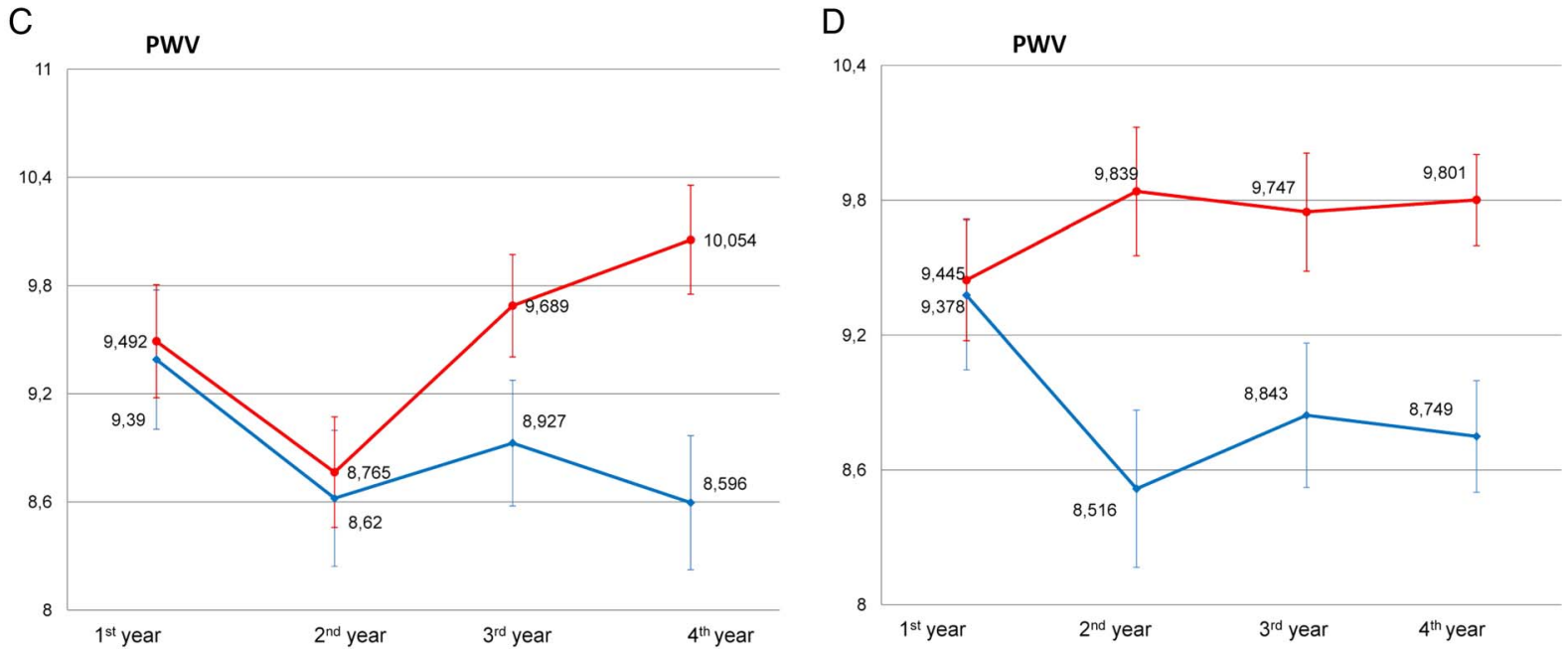

Figure 3 Estimated unadjusted means ( $\mathrm{A}$ and $\mathrm{C}$ ), and adjusted by age, gender, atherogenic index and office blood pressure (B and D) of IMT and PWV in patients with type 2 diabetes and metabolic syndrome. IMT, intima media thickness; PWV, pulse wave velocity. 
contrasts, statistical significance $(p \leq 0.01)$ is only reached in the first case.

\section{DISCUSSION}

Unlike previous studies that examined the prevalence of cardiovascular diseases in relation to glucose disorders, we analysed the difference between patients with type 2 diabetes or MetS in terms of vascular, renal and cardiac TOD. This study included a 4-year follow-up period of patients with type 2 diabetes or MetS. It showed an increase in carotid IMT and PWV TOD that is higher in type 2 diabetes than in MetS. There were no significant differences in the frequency of renal and cardiac TOD in type 2 diabetes. Participants with MetS have no significant increases in TOD.

In people with diabetes, the evolution of subclinical cardiovascular diseases is worse than in those with only an increased resistance to insulin without changes in blood sugar levels as in patients with MetS. ${ }^{3}$ The evolution of vascular parameters (IMT and PWV over time) is a controversial matter probably due to the control of cardiovascular risk factors and the influence of the drugs used to control it.

A meta-analysis of Lorenz et $a l^{26}$ (based on 1339 strokes from 16 studies) concluded that the association between IMT progression (evaluated with ultrasound and cardiovascular risk) and the risk of subsequent cardiovascular events in the general population has yet to be confirmed. An intensive intervention on people with diabetes with different cardiovascular risk factors over 2 years reduced the IMT, but no markers (including endothelial function parameters) were useful in predicting such changes. ${ }^{27}$

The Tromsø study had higher levels of IMT at follow-up in participants with MetS than in those without MetS. ${ }^{28}$ MetS predicted IMT progression in people 50 years of age and younger, but not in other age groups. This indicated that MetS may be involved in the initiation of the atherosclerotic process. In the European Lacidipine Study on Atherosclerosis (ELSA), ${ }^{29}$ IMT progression was slightly greater in patients with MetS. However, this was not significant after adjusting for other cardiovascular risk factors. Only patients with type 2 diabetes had an increase in $P W V \geq 12 \mathrm{~m} / \mathrm{s}$ during the monitoring period.

Our findings suggest that patients with increased insulin resistance did not have differences in CAIx and PAIx. These results are consistent with previously published $^{30}$ data in a Chinese cohort. ${ }^{30} 31$ The behaviour of ABI was similar in both patient groups both in terms of absolute $\mathrm{ABI}$ values and the percentage of patients with $A B I<0.9$. Similar data have been published in other studies with patients with type 2 diabetes. ${ }^{32-34}$ However, it must be remembered that in patients with diabetes, the standard threshold sensitivity (0.9) is lower, and thus the efficiency of ABI is limited.
This study has some limitations that must be considered. First, the number of participants per group limits the power of the analysis. Furthermore, these patients were not randomised, but involved consecutive sampling. The two groups are not fully balanced in terms of age (4 years of difference), which may influence the course. One remarkable point is that this study shows the differences in the progression of many parameters including IMT and PWV between 2 groups prospectively for 4 years.

This prospective study showed that the evolution of vascular TOD is different in participants with type 2 diabetes than in those with MetS. While IMT and PWV increased in type 2 diabetes, especially in diabetic women, these were not modified in MetS. The renal and cardiac TOD evolution, as well as the PAIx and CAIx, did not change in either group.

\section{Author affiliations}

${ }^{1}$ Primary Care Research Unit, The Alamedilla Health Center, Salamanca, Spain ${ }^{2}$ Castilla and León Health Service-SACYL, REDIAPP: Research Network on Preventive Activities and Health Promotion, Biomedical Research Institute of Salamanca (IBSAL), Salamanca, Spain

${ }^{3}$ Medicine Department, University of Salamanca, Salamanca, Spain

${ }^{4}$ Statistics Department, University of Salamanca, Salamanca, Spain

${ }^{5}$ Biomedical and Diagnostic Sciences Department, University of Salamanca, Salamanca, Spain

${ }^{6}$ LOD-DIABETES Group, REDIAPP: Research Network on Preventive Activities and Health Promotion, Salamanca, Spain

Acknowledgements The authors are grateful to all professionals participating in the LOD-DIABETES study. Coordinating Center: MÁG-M. La Alamedilla Health Center (Castilla y León Health Service-SACYL, Salamanca, Spain) CA-C, LG-S, MG-S, Carmen Castaño-Sanchez, Carmela Rodriguez-Martin, Benigna Sanchez-Salgado, Angela de Cabo Laso, ER-S, Jose Angel Maderuelo-Fernandez, Emilio Ramos-Delgado, MCP-A, JIR-R and LG-0.

Contributors MÁG-M designed the study, wrote the protocol, participated in fundraising, interpreted the results, prepared the manuscript draft, performed all analytical testing, interpreted the results and reviewed the manuscript and corrected the final version of the manuscript. JIR-R and CA-C participated in the study design, data collection and manuscript review. LG-S, MG-S, ER-S and JAM-F participated in the study design, interpretation of results and manuscript review. MCP-A participated in the analysis of results and final review of the manuscript. LG-O participated in the protocol design, fundraising, analysis of results and final review of the manuscript. All authors reviewed and approved the final version of the manuscript.

Funding The project has been funded by the Institute of Health Carlos III, (ISCIII) of the Ministry of Economy and Competitiveness (Spain) through the Network for Prevention and Health Promotion in Primary Care (redIAPP, RD12/0005), co-financed with European Union ERDF funds and the Autonomous Government of Castilla and León in 2009 and 2013 (GRS. 428/ A/09; GRS 768/B/13), and the Intensification of Research Program.

Competing interests None declared.

Patient consent Obtained.

Ethics approval An independent ethics committee of health area of Salamanca (Spain).

Provenance and peer review Not commissioned; externally peer reviewed.

Data sharing statement No additional data are available.

Open Access This is an Open Access article distributed in accordance with the Creative Commons Attribution Non Commercial (CC BY-NC 4.0) license, 
which permits others to distribute, remix, adapt, build upon this work noncommercially, and license their derivative works on different terms, provided the original work is properly cited and the use is non-commercial. See: http:// creativecommons.org/licenses/by-nc/4.0/

\section{REFERENCES}

1. Novo S, Peritore A, Guarneri FP, et al. Metabolic syndrome (MetS) predicts cardio and cerebrovascular events in a twenty years follow-up. A prospective study. Atherosclerosis 2012;223:468-72.

2. Barnett KN, Ogston SA, McMurdo ME, et al. A 12-year follow-up study of all-cause and cardiovascular mortality among 10,532 people newly diagnosed with type 2 diabetes in Tayside, Scotland. Diabet Med 2010;27:1124-9.

3. Barzilay JI, Spiekerman CF, Kuller LH, et al. Prevalence of clinical and isolated subclinical cardiovascular disease in older adults with glucose disorders: the Cardiovascular Health Study. Diabetes Care 2001;24:1233-9.

4. Abate N, Sallam HS, Rizzo M, et al. Resistin: an inflammatory cytokine. Role in cardiovascular diseases, diabetes and the metabolic syndrome. Curr Pharm Des 2014;20:4961-9.

5. Guo SX, Yan YZ, Mu LT, et al. Association of serum free fatty acids with hypertension and insulin resistance among rural uyghur adults in far Western China. Int J Environ Res Public Health 2015;12:6582-90.

6. Xanthakis V, Sung JH, Samdarshi TE, et al. Relations between subclinical disease markers and type 2 diabetes, metabolic syndrome, and incident cardiovascular disease: the Jackson Heart Study. Diabetes Care 2015;38:1082-8.

7. Zhang $\mathrm{T}$, Zhang $\mathrm{H}$, Li S, et al. Impact of adiposity on incident hypertension is modified by insulin resistance in adults: longitudinal observation from the Bogalusa Heart Study. Hypertension 2016:67:56-62.

8. Chirinos JA, Segers P, Gillebert TC, et al. Central pulse pressure and its hemodynamic determinants in middle-aged adults with impaired fasting glucose and diabetes: the Asklepios study. Diabetes Care 2013;36:2359-65.

9. Einarson TR, Hunchuck J, Hemels M. Relationship between blood glucose and carotid intima media thickness: a meta-analysis Cardiovasc Diabetol 2010;9:1475-2840.

10. Vlachopoulos C, Aznaouridis K, O'Rourke MF, et al. Prediction of cardiovascular events and all-cause mortality with central haemodynamics: a systematic review and meta-analysis. Eur Heart J 2010;31:1865-71.

11. Fowkes FG, Murray GD, Butcher I, et al. Ankle brachial index combined with Framingham Risk Score to predict cardiovascular events and mortality: a meta-analysis. JAMA 2008;300:197-208.

12. Somaratne JB, Whalley GA, Poppe KK, et al. Screening for left ventricular hypertrophy in patients with type 2 diabetes mellitus in the community. Cardiovasc Diabetol 2011;10:1475-2840.

13. Fox CS, Matsushita K, Woodward M, et al. Associations of kidney disease measures with mortality and end-stage renal disease in individuals with and without diabetes: a meta-analysis. Lancet 2012;380:1662-73.

14. Goderis G, Van Pottelbergh G, Truyers C, et al. Long-term evolution of renal function in patients with type 2 diabetes mellitus: a registry-based retrospective cohort study. BMJ Open 2013;3:004029.

15. Gomez-Marcos MA, Recio-Rodriguez JI, Rodriguez-Sanchez E, et al Central blood pressure and pulse wave velocity: relationship to target organ damage and cardiovascular morbidity-mortality in diabetic patients or metabolic syndrome. An observational prospective study. LOD-DIABETES study protocol. BMC Public Health 2010;10:143.

16. Sekitani $\mathrm{Y}$, Hayashida N, Kadota K, et al. White blood cell count and cardiovascular biomarkers of atherosclerosis. Biomarkers 2010;15:454-60.

17. Grundy SM, Cleeman JI, Daniels SR, et al. Diagnosis and management of the metabolic syndrome: an American Heart
Association/National Heart, Lung, and Blood Institute Scientific Statement. Circulation 2005;112:2735-52.

18. Gomez-Marcos MA, Recio-Rodríguez JI, Patino-Alonso MC, et al. Yearly evolution of organ damage markers in diabetes or metabolic syndrome: data from the LOD-DIABETES study. Cardiovasc Diabetol 2011;10:90.

19. World Medical Association. World Medical Association Declaration of Helsinki: ethical principles for medical research involving human subjects. JAMA 2013;310:2191-4.

20. Mancia G, Fagard R, Narkiewicz K, et al. 2013 ESH/ESC Guidelines for the management of arterial hypertension: the Task Force for the management of arterial hypertension of the European Society of Hypertension (ESH) and of the European Society of Cardiology (ESC). J Hypertens 2013;31:1281-357.

21. Mancia G, De Backer G, Dominiczak A, et al. 2007 Guidelines for the management of arterial hypertension: the task force for the management of arterial hypertension of the European Society of Hypertension (ESH) and of the European Society of Cardiology (ESC). J Hypertens 2007;25:1105-87.

22. Munir S, Guilcher A, Kamalesh T, et al. Peripheral augmentation index defines the relationship between central and peripheral pulse pressure. Hypertension 2008;51:112-18.

23. Gómez-Marcos MA, Recio-Rodríguez JI, Patino-Alonso MC, et al. Protocol for measuring carotid intima-media thickness that best correlates with cardiovascular risk and target organ damage. Am J Hypertens 2012;25:955-61.

24. Levey AS, Bosch JP, Lewis JB, et al. A more accurate method to estimate glomerular filtration rate from serum creatinine: a new prediction equation. Modification of diet in renal disease study group. Ann Intern Med 1999;130:461-70.

25. Okin PM, Roman MJ, Devereux RB, et al. Electrocardiographic identification of increased left ventricular mass by simple voltage-duration products. J Am Coll Cardiol 1995;25 417-23.

26. Lorenz MW, Polak JF, Kavousi M, et al. Carotid intima-media thickness progression to predict cardiovascular events in the general population (the PROG-IMT collaborative project): a meta-analysis of individual participant data. Lancet 2012;379:2053-62.

27. Tripolt NJ, Narath $\mathrm{SH}$, Eder M, et al. Multiple risk factor intervention reduces carotid atherosclerosis in patients with type 2 diabetes. Cardiovasc Diabetol 2014;13:95.

28. Herder M, Arntzen KA, Johnsen $\mathrm{SH}$, et al. The metabolic syndrome and progression of carotid atherosclerosis over 13 years. The Tromso study. Cardiovasc Diabetol 2012;11:77.

29. Zanchetti $A$, Hennig $M$, Baurecht $H$, et al. Prevalence and incidence of the metabolic syndrome in the European Lacidipine Study on Atherosclerosis (ELSA) and its relation with carotid intima-media thickness. J Hypertens 2007;25:2463-70.

30. Zhang M, Bai Y, Ye P, et al. Type 2 diabetes is associated with increased pulse wave velocity measured at different sites of the arterial system but not augmentation index in a Chinese population. Clin Cardiol 2011;34:622-7.

31. Johansen NB, Charles M, Vistisen D, et al. Effect of intensive multifactorial treatment compared with routine care on aortic stiffness and central blood pressure among individuals with screen-detected type 2 diabetes: the ADDITION-Denmark study. Diabetes Care 2012;35:2207-14.

32. Ito H, Komatsu Y, Mifune M, et al. The estimated GFR, but not the stage of diabetic nephropathy graded by the urinary albumin excretion, is associated with the carotid intima-media thickness in patients with type 2 diabetes mellitus: a cross-sectional study. Cardiovasc Diabetol 2010;9:18.

33. Dachun $X$, Jue $L$, Liling $Z$, et al. Sensitivity and specificity of the ankle-brachial index to diagnose peripheral artery disease: a structured review. Vasc Med 2010;15:361-9.

34. Potier L, Abi Khalil C, Mohammedi K, et al. Use and utility of ankle brachial index in patients with diabetes. Eur $J$ Vasc Endovasc Surg 2011;41:110-16. 